\title{
The fish rots from the head down: a test of the trickle-down model of abusive supervision
}

Trickle-down model of abusive supervision

\author{
Hannah Vivian Osei and Felicity Asiedu-Appiah
}

Department of Human Resource and Organisational Development, KNUST School of Business, Kwame Nkrumah University of Science and Technology, Kumasi, Ghana, and

\author{
Perpetual Akosuah Anyimaduah Amoah \\ Adansi Rural Bank, Fomena-Adansi, Ghana
}

\begin{abstract}
Purpose - A major paradigm shift focusing on the dark side of leadership has generated lots of concern for organizations as leadership has cascading effects on employees' behaviour. This study aims to understand negative behaviours in the organization as a system of interrelated interaction initiated from the top which trickles down to employees.

Design/methodology/approach - Drawing on the theories of social exchange and norms of reciprocity, social learning and displaced aggression, this study models how and when abusive supervision relates to employees' task performance. The model is empirically tested and extended to cover mediation and moderation processes. Drawing data from 218 bank supervisors and employees, this study uses the structural equation modelling to analyse a trickle-down model of abusive supervision.

Findings - Results from multi-waved, multi-sourced data indicated a mediating effect on the abusive supervisionperformance relationships and provided support for employees' guilt proneness and emotional dissonance as moderators. Overall, the results provided support for a moderated mediation relationship in the trickle-down model.

Originality/value - This study provides new knowledge into the potential boundary conditions of employees' guilt proneness and emotional dissonance in affecting the relationship between abusive supervision, counterproductive work behaviour and task performance.
\end{abstract}

Keywords Abusive supervision, Employees' task performance, Counterproductive work behaviour, Guilt proneness, Emotional dissonance, Trickle-down effect, Ghana, Banks

Paper type Research paper

\section{Introduction}

The domain of leadership has seen a plethora of beneficial effects of leadership; however, recent interest in leadership has seen a major paradigm shift from the beneficial effects to the dark

(C) Hannah Vivian Osei, Felicity Asiedu-Appiah and Perpetual Akosuah Anyimaduah Amoah. Published in Organization Management Journal. Published by Emerald Publishing Limited. This article is published under the Creative Commons Attribution (CC BY 4.0) licence. Anyone may reproduce, distribute, translate and create derivative works of this article (for both commercial and non-commercial purposes), subject to full attribution to the original publication and authors. The full terms of this licence maybe seen at http://creativecommons.org/licences/by/4.0/legalcode

The authors acknowledge Ms Angelina Osei of the Ghana Institute of Languages for proof reading this manuscript. Furthermore, they are grateful to the anonymous reviewers for their constructive and developmental feedback.

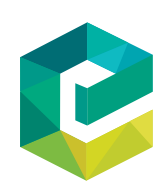

Received 3 March 2020 
$\mathrm{OMJ}$

$18,3 / 4$

side of leadership (An \& Wang, 2016; Lian, Ferris, Morrison \& Brown, 2014a; KarakitapoğluAygün \& Gumusluoglu, 2013; Mawritz, Mayer, Hoobler, Wayne \& Marinova, 2012). Various terminologies have been used to capture the dark side of leadership, including abusive supervision (Tepper, 2000), despotic leadership (Aronson, 2001), petty tyranny (Ashforth, 1994) and supervisor undermining (Duffy, Ganster \& Pagon, 2002). The notion of "bad leaders" is raising increasing concern for organizations (Hoobler \& Hu, 2013) and this notion is very important to researchers and practitioners as leadership behaviour is believed to have cascading effects (Mayer, Kuenzi, Greenbaum, Bardes \& Salvador, 2009). Masterson (2001) was the first to demonstrate the "trickle-down effects" of superior's attitudes, behaviours and perception on subordinates' attitudes, behaviours and perceptions. This trickle-down effect influences the organizational climate and has consequences on subordinates' performance. According to Osei, Osei-Kwame and Osei Amaniampong (2017), authorities in their everyday dealings with workers create the environments through which perceived trust, ethics and justice are formed. These perceptions affect the work atmosphere and the workers' behaviour. Extant research has demonstrated the trickle-down effect across various phenomena such as abusive supervision (Mawritz et al., 2012), psychological contract breach and violation (Bordia, Restubog, Bordia \& Tang, 2010), justice perceptions (Ambrose, Schminke \& Mayer, 2013; Wo, Ambrose \& Schminke, 2015), aggression (Burton \& Hoobler, 2011), deviance behaviours (Wei \& Si, 2013), creativity (Liu, Liao and Loi, 2012) and performance (Xu et al., 2012).

A burgeoning body of research has focused on abusive supervision as a typical manifestation of destructive leadership with detrimental effects on subordinates and organizations. Abusive supervision is defined as "subordinates' perceptions of the extent to which their supervisors engage in the sustained display of hostile verbal and nonverbal behaviours, excluding physical contact" (Tepper, 2000, p. 178). Some of the behavioural descriptions of abusive supervision include: humiliating or ridiculing someone in front of others, the silent treatment, withholding needed information, threatening employees of job loss, aggressive eye contact, explosive outbursts (e.g. screaming or yelling at someone) and using derogatory names (Zellars, Tepper \& Duffy, 2002). The effects of abusive supervision can be costly to both employers and employees (Tepper, Moss \& Duffy, 2011). Abused employees experience anger, fear, destructive anxiety, depression, hostility and psychological distress (Restubog, Scott \& Zagenczyk, 2011). According to Abas and Otto (2016), the hierarchical position of an instigator of workplace mistreatment shapes the target's attitudes. Abusive supervision has also been linked to various behavioural and attitudinal outcomes such as work engagement, organizational commitment, organizational citizenship behaviour, counterproductive work behaviour (CWB) and other employee deviance behaviours (Lian et al., 2014a; Valle, Kacmar, Zivnuska \& Harting, 2019). Various models on the trickle-down effects of abusive supervision have focused mostly on one mechanism and few have used more than one theory to provide explanations of the trickledown effects of abusive supervision (Mawritz et al., 2012; Wo et al., 2015).

Nevertheless, there have been calls to investigate responses of mistreatment as a system of interrelated interactions (Andersson \& Pearson, 1999). Accordingly, we examine a theoretical model of mediating and moderating mechanisms using multiple theories to explain the interrelated interactions in the abusive supervision - performance relationship. The present study extends research by proposing that employees retaliate abusive supervision with CWB which trickles down to employees' performance. Employees also model the behaviours of supervisors and learn from these negative behaviours. Empirical evidence suggests that employees engage in upward hostility against their supervisors (Lian, Brown, Ferris, Liang, Keeping \& Morrison, 2014b). However, directly confronting an abusive supervisor may result in further counter-retaliation, punishment or loss of reward 
because of the differences in power (Tepper, 2007, 2009). Thus, engaging in supervisordirected retaliation seems irrational and can make a bad situation worse. We argue that for fear of the consequences of retaliating directly to abusive supervisors, employees displace their frustration on the organization through CWB. To provide a better understanding of the effects of abusive supervision, we propose emotions as one of the important but ignored aspects of the system of mistreatment. Accordingly, we extend our hypotheses to cover moderated mediation by proposing guilt-proneness, a self-conscious emotion which insists on following moral standards; and emotional dissonance, a work-conscious emotion originating from a conflict between expressed and experienced emotions, as moderating mechanisms. Guilt proneness is an emotional trait characterized by a person's negative feeling about wrongdoing, even when the act was done in private (Cohen, Panter \& Turan, 2013; Cohen, Wolf, Panter \& Insko, 2011). We propose that employees' guilt-proneness will attenuate the negative effects of abusive supervision on CWB and employees' performance. To further broaden our understanding of the cascading effects of abusive supervision on subordinates' performance through the CWB, we propose emotional dissonance as a moderator. Service occupations are emotionally demanding as workers are expected to express organizationally desired emotions, such as courtesy, that may not represent their true feelings (Molino, Emanuel, Zito, Ghislieri, Colombo \& Cortese, 2016; van Gelderen, Konijn \& Bakker, 2017). We postulate that in high emotional dissonance work environments, employees engage less in CWB when abused and this attenuates the negative effects of CWB on performance. Figure 1 presents our hypothesized model.

The overarching goal of this study is to enrich the theoretical and empirical understanding of when and how abusive supervision trickles down negatively to affect employees' behaviours. The purpose of this study is to understand how abusive supervision affects job performance. Secondly, the study seeks to determine the generalizability of this mediation across different predispositions to experience guilt-proneness and emotional dissonance. This study is in response to the assertion by Burton and Hoobler (2011) and Nandkeolyar, Shaffer, Li, Ekkirala and Bagger (2014) that little is known about how subordinate factors moderate the effect of abusive supervision and work outcomes. Tepper, Mitchell, Haggard, Kwan and Park (2015) also calls for the exploration of moderators such as dispositional inclinations to experience guilt and shame in the wake of performing dysfunctional acts. Thirdly, this study contributes to the trickle-down debate of abusive leadership from four theoretical perspectives - social exchange (Blau, 1964), norms of reciprocity (Gouldner, 1960), social learning (Bandura, 1977) and displaced aggression (Dollard, Doob, Miller, Mowrer \& Sears, 1939). These four theories are the most cited for explaining trickle-down effects (Wo et al., 2015). This study integrates these four theoretical perspectives in a comprehensive framework (Figure 1) to understand the pathways through which abusive supervision influences employees' performance. Conceptualizing a simultaneous model of multiple mechanisms of the effects of abusive supervision provides evidence on when, why and how abusive supervision leads to negative outcomes. This

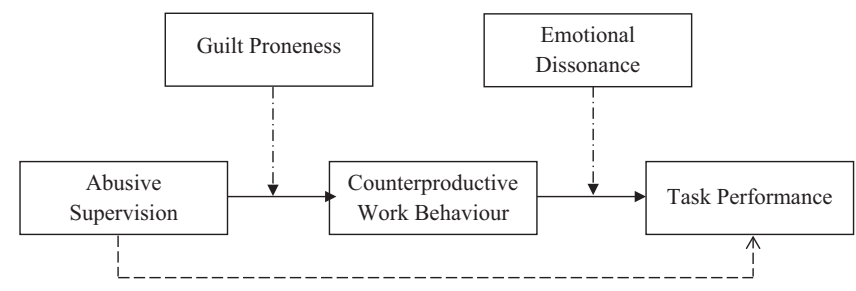

Trickle-down model of abusive supervision

123

\section{$-$}


$\mathrm{OMJ}$

$18,3 / 4$

simultaneous model is important in understanding the negative employees' behaviour in the workplace.

\section{Theoretical and hypotheses development}

\section{Abusive supervision}

Supervisors and subordinates share the responsibility of working together cooperatively; however,

some supervisors display behaviours that can be characterized as abusive, undermining, bullying or tyrannical (Zellars et al., 2002). Tepper (2000, p. 178) provides a comprehensive definition of abusive supervision as "subordinates' perceptions of the extent to which their supervisors engage in the sustained display of hostile verbal and nonverbal behaviours, excluding physical contact". Examples of such verbal and non-verbal behaviours include rudeness, lying, humiliating or ridiculing, threatening job loss, screaming or yelling, invasion of privacy, aggressive eye contact, withdrawing and silent treatment. Abusive supervision has been characterized as a subjectively perceived phenomenon. This perception suggests that the consequences of abusive supervision vary among employees and depend on how individuals uniquely interpret and respond to supervisory abuse (Mackey, Kane, Perrewe \& Gallagher, 2013).

Abusive supervision has been linked to numerous negative employees' outcomes in the workplace, including stress-related consequences, psychological distress and negative attitudes (Tepper, 2000, 2007; Zellars et al., 2002). Mostly, victims of abusive supervision hold the organization partially responsible for a supervisor's bad behaviour (Shoss, Eisenberger, Restubog \& Zagenczyk, 2013). Undoubtedly, abusive supervision has effects on numerous deleterious outcomes, including organizational deviance, low job satisfaction, decreased organizational citizenship behaviours and increased intentions to quit (Thau, Bennett, Mitchell \& Marrs, 2009). It is against this background that this study is carried out to determine the trickle-down effects of abusive supervision.

\section{Abusive supervision and employees' job performance}

From the social exchange theory (Blau, 1964) and the norms of reciprocity (Gouldner, 1960), relationships are negotiated based on rewards and costs. Individuals feel obliged to return favours and likewise hostilities and negative actions. One negative behaviour that has surged interest and has been widely studied with the social exchange theory is abusive supervision. When subordinates perceive abusive supervision, they reciprocate with negative behaviours which are non-explicitly bargained. According to the social learning theory (Bandura, 1977), individuals learn from the social setting and one another by observing and retaining as well as reproducing what has been learnt. Thus, when supervisors engage in mistreatments such as abusive supervision, subordinates are motivated to engage in negative behaviours such as poor job performance. This motivation is because subordinates may not be able to aggress against their supervisors in a tit-for-tat manner, especially in high-power distance cultures, as it may be unwise or impossible. Employees engage in indirect aggression by avoiding work or doing what is minimally acceptable to harm the organization. Aggression is any behaviour that is intended to harm either physically, verbally, relationally, directly or indirectly (Warburton \& Anderson, 2015). In support of our argument, abusive supervision has been found to negatively affect bank employees' creativity in the USA (Liu et al., 2012). Likewise, Dartey-Baah and Ampofo (2015) found among Ghanaian bank employees that positive leadership, like transformational leadership, rather inspires confidence in subordinates and leads to positive employees' outcomes. Negative supervision, like abusive supervision, presents a threat to employees' competence, confidence and capacity (Morrison \& Wonnacott, 2010) and 
negatively affect employees' performance (Xu, Huang, Lam \& Miao, 2012; Walter, Lam, Van der Vegt, Huang \& Miao, 2015). Thus, we hypothesize:

H1. Abusive supervision negatively relates to employees' performance.
Trickle-down model of abusive supervision

\section{Abusive supervision, counterproductive work behaviour and employees performance}

According to the social learning theory (Bandura, 1977), individuals emulate the behaviours of others in a social context by observing and modelling one another. Subordinates learn from their supervisors' behaviours in work settings. In line with the theory of social exchange (Blau, 1964) and the norms of reciprocity (Gouldner, 1960), a natural response to abusive treatment from a supervisor, is to retaliate against the supervisor (Liang et al., 2018). These reciprocal exchanges may be homoeomorphic (similar in form) or heteromorphic (similar values but different in form) (Lyons \& Scott, 2012). However, from the theory of displaced aggression (Dollard et al., 1939), in circumstances where individuals cannot aggress against the source of their provocation, they take it out on a less powerful or more available target.

Because of power differences, subordinates rather displace their aggression on their organizations by engaging in CWB. CWB takes many forms such as verbal abuse, lying, theft and sabotage, refusing to cooperate and withdrawing of effort (Anjum \& Parvez, 2013). Empirical evidence supports a positive relationship between abusive supervision and CWB (An \& Wang, 2016; Tepper, Carr, Breaux, Geider, Hu \& Hua, 2009; Ju, Xu, Qin \& Spector, 2019). Findings across different contexts confirm this positive relationship (Eschleman, Bowling, Michel \& Burns, 2014; Lian et al., 2014a, 2014b; Sulea, Fine, Fischmann, Sava \& Dumitru, 2013; Valle et al., 2019). We, therefore, hypothesize that:

H2a. Abusive supervision positively relates to CWB.

Aggressive behaviours, such as CWB, are negative acts committed within the workplace which target individuals and the workplace itself with the intent to harm (Hershcovis, 2011; Hershcovis et al., 2007). In chronicling the study of CWB targeting organizations, Klotz and Buckley (2013) assert that employees have found more ways of engaging in CWB. These volitional behaviours such as being late without permission, stealing office supplies, being rude to clients and production deviance harm organizations and employees (Spector, Fox, Penney, Bruursema, Goh \& Kessler, 2006). According to Spector and Fox (2010), employees may engage in CWB as a well-planned behaviour while others may opt for it as emotional retaliation or reciprocity. Over time, this behaviour or retaliation becomes the norm that other employees emulate, thereby decreasing productivity. In a study by Macovei (2016), CWB was found to correlate with a decrease in the quality of employees' work and an increase in the frequency of lower than expected performance. Empirical evidence exists to support the negative relationship between CWB and employee performance (Penney \& Spector, 2005; Wei \& Si, 2013):

$H 2 b$. CWB negatively relates to employees' performance.

\section{Counterproductive work behaviour as mediator in abusive supervision and job performance}

Social exchange processes within organizations begin when a member (e.g. supervisor), treats a target individual (e.g. subordinate) positively or negatively (Eisenberger, Lynch, 
$\mathrm{OMJ}$

$18,3 / 4$

126

Aselage \& Rohdieck, 2004). Employees tend to learn from and engage in such behaviours in their social context (Bandura, 1977). A negative initiating action from a supervisor to a subordinate generates negative retribution responses (Gouldner, 1960) such as CWB, which negatively affects performance. CWB is a negative work behavioural response which can result from abusive supervision, which is hedonically negative (Cropanzano, Anthony, Daniels \& Hall, 2017). From the displaced aggression theory, abused subordinates rather aggress on the organization by engaging in behaviours that harm the organization (e.g. CWB and poor performance). Such deviant behaviours are hedonically negative, which violate performance-enhancing norms with deleterious consequences on employees' performance (Cropanzano et al., 2017).

Few studies have been carried out on mediating roles in abusive supervision and employee performance (Aryee, Sun, Chen \& Debrah, 2008; Mawritz et al., 2012; Zhu, Lian, Hao \& Ding, 2015). Studies reveal that subordinates respond negatively to supervisor mistreatment (Lian et al., 2014a, 2014b; Tepper, 2000; Thau et al., 2009). Abusive supervision has been associated with abusive employee behaviours such as work deviance (Mawritz et al., 2012; Valle et al., 2019). Ju et al. (2019) consistently found from multi-studies that abusive supervision triggers CWB. Other studies have also reported negative effects of CWB on employees' performance (Wei \& Si, 2013; Penney \& Spector, 2005). We compliment the various findings and argue for CWB as one of the mediators in the trickle-down effects of abusive supervision on employee performance:

H2c. CWB partially mediates the relationship between abusive supervision and employees' job performance.

\section{Interactive effect of abusive supervision and guilt proneness}

At the workplace, there are various homoeomorphic and heteromorphic social exchanges (Blau, 1964; Gouldner, 1960; Lyons \& Scott, 2012) which are learnt by employees (Bandura, 1977). When subordinates are unable to aggress directly against their supervisors when abused, they rather displace their aggression on their organization (Dollard et al., 1939) through dysfunctional behaviours. Although abusive supervision leads to dysfunctional work behaviours such as CWB (An \& Wang, 2016; Sulea et al., 2013), the deleterious effects can be attenuated. According to Robinson and Bennett (1995), a given provocation may lead to deviant behaviour (e.g. CWB) depending on the presence of constraints or controls that inhibit such behaviour. One of such constraints is an individual's guilt-proneness. Guilt proneness is an emotional trait (Cohen et al., 2013) characterized with a negative feeling about one's wrongdoing, even when the act was done in private (Cohen et al., 2011). Guilt has been associated with enhancing relationships through the suppression of anger and blame. Empirical studies suggest that high guilt-prone employees are predisposed to experiencing negative feelings about personal wrongdoings, and thus engage less frequently in CWB and other workplace deviance behaviours (Cohen et al., 2013; Kim \& Cohen, 2015). Low guiltprone employees respond to negative work environments, such as abusive supervision, by engaging in unethical behaviours (Kim \& Cohen, 2015). Recent research confirms that subordinates' differences affect their perception of and reaction to abuse (Martinko, Harvey, Brees \& Mackey, 2013). In response to calls by Tepper et al. (2015) for research on dispositional inclination as moderator in the effects of abusive supervision and based on the empirical evidence, we propose that employees' guilt-proneness will constrain the negative effect of abusive supervision on CWB such that workers high on guilt-proneness will engage less in CWB. Accordingly, we hypothesize: 
H3a. Guilt proneness negatively relates to CWB.

$H 3 b$. Guilt proneness moderates the negative relationship between abusive supervision and CWB such that the relationship is weaker for those high rather than low in guilt-proneness.

We extend the preceding argument by proposing a moderated mediation relationship in the trickle-down effect of abusive supervision. It has already been established that abusive supervision leads to poor performance (Xu et al., 2012) and that this relationship is mediated by the CWB. The relationship between abusive supervision and CWB has been argued to be moderated by guilt-proneness. Guilt activates a sense of responsibility, ethical behaviour and loyalty to one's job. Employees prone to guilt put up their best performance and engage less in CWB and other unethical behaviours (Flynn \& Schaumberg, 2012; Kim \& Cohen, 2015). People prone to guilt forgive and reconcile (Jordan, Flynn \& Cohen, 2015) to support collective goals at the expense of personal goals (Cohen et al., 2013). Thus, when abused by supervisors, employees high in guilt-proneness, are likely to forgive supervisors' transgressions (Jordan et al., 2015) and not to reciprocate with CWB (Cohen et al., 2013) as well as fulfil expectations concerning their performance (Flynn \& Schaumberg, 2012). On the contrary, employees with low guilt-proneness are expected to engage more in CWBs and less in task performance. In line with the above, we, therefore, propose the following:

H3c. Guilt proneness positively relates to employees' performance.

$H 3 d$. The interactive effect of abusive supervision and guilt-proneness on job performance is mediated by CWB, such that the impact of abusive supervision on CWB is greater when guilt-proneness levels are low, and higher levels of CWB are associated with lower levels of employees' performance.

\section{Interactive effect of counterproductive work behaviour and emotional dissonance}

The service sector is characterized by high levels of emotional dissonance. Zapf (2002) defines emotional dissonance as the structural discrepancy between felt emotions and expressed emotions in the working environment to conform to display rules. These "display rules" or "feeling rules" describe the acceptable behaviour in a work context (Hochschild, 1983) and the "organizationally desired emotions during interpersonal transactions" (Morris \& Feldman, 1996, p. 987). The requirement for friendly and courteous treatment of customers regardless of customers' behaviour, as expected of service providers such as banks, is thought of as a significant aspect of the job and as an in-role necessity (Bailey \& McCollough, 2000; Diefendorff, Richard \& Croyle, 2006; Zapf \& Holz, 2006). Exhibition of positive emotions to "cool people" are impulsive and requires less effort because employees genuinely experience these emotions. However, anger-provoking events demand effort and control and result in expressing emotions that are contrary to truly felt emotions (Grandey, Kern \& Frone, 2007). Employees suffer from emotional dissonance as a result of having to comply with expected emotional demands (van Gelderen et al., 2017), which is different from their real or felt emotions (Yagil, 2012). Emotional dissonance, thus, is an outcome of the social exchanges and expectations at work. Previous studies have found a negative relationship between emotional dissonance and job performance (Bakker \& Heuven, 2006; Paunov, 2010). This negative relationship is because employees feel alienated from the work and easily get emotionally exhausted. Some researchers consider emotional dissonance as a psychological cost (Yagil, 2012) and a stressor with harmful consequences (Crego, Martinez-Inigo \& Tschan, 2013).

Abused employees may use CWBs as coping tactics, retaliatory measures and means to displace aggression. However, employees in emotionally demanding roles - requiring
Trickle-down model of abusive supervision 
$\mathrm{OMJ}$ $18,3 / 4$

frequent and intense interpersonal encounters - are expected to display organizationally desired emotions and behaviours and thus, will engage less in CWB. CWB is also known to negatively affect employee performance (Penney \& Spector, 2005). Based on the preceding arguments, we propose that the effect of $\mathrm{CWB}$ on performance will be weaker for employees with high emotional dissonance. On the contrary, for employees with low emotional dissonance, the effect of CWB on performance will be strong:

H4a. Emotional dissonance negatively relates to employees' performance.

H4b. Emotional dissonance moderates the relationship between CWB and employees' performance, such that the relationship is weaker when emotional dissonance levels are high rather than low.

This study further proposes that the trickle-down of abusive supervision to poor employees' performance through CWB is dependent on the work context. In service organizations such as the banks, employees are expected to display positive emotions, sometimes contrary to how they feel, leading to emotional dissonance. Emotional dissonance creates an unstable psychological state with negative outcomes (Yagil, 2012) such as abusive supervision (Yam, Fehr, Keng-Highberger, Klotz \& Reynolds, 2016) and other deviant behaviours. In such work contexts, abusive treatment from supervisors violates the expectation of positive behavioural exchanges. This violation, from a social exchange perspective, should stimulate retaliation (Tepper et al., 2015) to restore balance in the relationship. In line with empirical findings, employees engage in CWB to feel better in response to negative workplace events and stressful situations (Shoss, Jundt, Kobler \& Reynolds, 2016). CWB has also been found to negatively affect performance (Wei \& Si, 2013). However, because of social norms on displaying appropriate behaviours, employees may be inhibited in displacing their aggression through $\mathrm{CWB}$ in service organizations. Thus, the expected negative effect of CWB on performance will be attenuated in a high dissonance work context. Alternatively, in emotionally arduous roles, employees will engage more in CWB when abused and this will increase the negative effect of CWB on performance. Based on the preceding arguments, we propose to test the following:

H4c. The indirect effect of CWB in the abusive supervision-employees' performance relationship is moderated by emotional dissonance such that the impact of CWB on employees' performance is weaker when emotional dissonance levels are high rather than low.

\section{Method}

Sample and procedure

The research was carried out in the banking sector in a developing country. Workers in this sector work directly with customers, managing accounts, increasing the bank's portfolio through increases in customers' deposit levels and the number of customers, appropriately interacting with customers and leading all sales aspects (promotion of products such as foreign currency, internet banking promotion and bank assurance) of the banks. Ghana's banking sector is highly competitive and open and crowded (Oxford Business Group, 2016). For banks to survive the competition, workers, who are the main interface between banks and customers must render quality services and perform effectively. These workers are also expected to exhibit positive emotions irrespective of their true emotions. It is from this contextual background that this study was undertaken.

The researcher adopted three-wave cross-sectional case study design. The first and second studies obtained measures from employees while the third study obtained measures 
from supervisors. The case study organization was contacted for permission to research the organization. Upon agreeing to the request, the study targeted supervisors, and all the permanent and contract employees (263). Participants voluntarily responded to structured questionnaires administered by one of the authors over three weeks. Employees rated their immediate supervisors on the abusive supervision items while supervisors, in the second study, rated the CWB and performance of their employees. Out of the sample, 218 usable questionnaires were included in the study representing a response rate of $82.9 \%$. From the descriptive statistics, $58 \%$ of the employees were contract staff, and $42 \%$ were permanent full-time staff (standard deviation $[\mathrm{SD}]=0.50$ ). All the supervisors were permanent staff. Fairly more than half of all of the respondents (52\%) were males, whereas $48 \%$ were females. More than half of all the respondents (53.2\%) were aged between 26 and 35 years and less than $1.5 \%$ were aged between 46 and 55 years ( $\mathrm{SD}=0.85)$. The study also found that $22 \%$ of the respondents had diploma education, $47.7 \%$ had bachelor's degrees and $4.6 \%$ had a master's degree $(\mathrm{SD}=0.94)$. Furthermore, $66 \%$ of the respondents were single, $27 \%$ were married, $6 \%$ were divorced and $1 \%$ were separated $(\mathrm{SD}=1.32)$. More than half of the respondents had work tenure between 1 and 5 years $(50.9 \%), 16.5 \%$ had worked between 6 and 10 years and $12 \%$ had more than 10 years of working experience. It, therefore, suffices that respondents with enough working experience and for that matter, better assessment of the study areas, were sampled in the study.

\section{Measures}

All measures were administered in English. The alpha reliabilities of the dimensions of the measures are reported in Table 1.

\section{Abusive supervision}

We used 12 items of Tepper's (2000) 15-item questionnaire after subjecting the 15 items to confirmatory factor analysis (CFA). Subordinates were requested to answer these questions with their immediate supervisors as referent, based on a seven-point Likert scale ranging from

Construct

Factor loadings

\section{$C W B$}

Indicator 1

Indicator 2

Guilt proneness

Indicator 1

0.784

Indicator 2

Task performance

Indicator 1

Indicator 2

Emotional dissonance

Indicator 1

Indicator 2

Abusive supervision

Indicator 1

Indicator 2

Table 1. Second-order CFA

\section{Trickle-down model of abusive supervision}

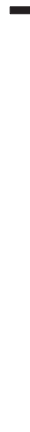


$\mathrm{OMJ}$ $18,3 / 4$

"not at all recorded" to "very much so". Sample items are "my boss tells me my thoughts or feelings are stupid" and "my boss puts me down in front of others". Following prior research, abusive supervision has been studied subjectively from the subordinates' view and measured with an index of the abusive supervision dimensions (Aryee et al., 2008; Mawritz et al., 2012).

\section{Counterproductive work behaviour}

We used 10 items from the 15-item questionnaire by Spector and Fox (2005) to measure CWB after subjecting the items to CFA. Supervisors rated the frequency of subordinates' engagement in the CWB on a five-point Likert scale ranging from 1 (never) to 5 (every day). Sample items are "employees purposely waste employer's materials/supplies" and "employees usually report to work late without permission".

\section{Emotional dissonance}

Subordinates answered the five-item emotional dissonance subscale from the Frankfurt Emotion Work Scales, which assessed the level of suppression of organizationally undesirable emotions and the display of unfelt emotions. Sample items include "how often in your job do you have to display emotions that do not agree with your true feelings?" and "how often in your job do you have to suppress emotions to appear "neutral" on the outside?".

\section{Guilt proneness}

Guilt proneness was measured with five items developed based on the guilt-proneness scale by Cohen, Kim and Panter (2014) based on employees' reaction to work situations. Samples of the items are "you give a bad presentation at work. Afterwards, your supervisor tells your co-workers it was your fault that the bank had made losses. What is the likelihood that you will feel incompetent?" and "you treat a co-worker or a customer unfairly, how likely will you feel remorse about your behaviour?".

\section{Job performance}

We used seven items for job performance, which were developed from literature and based on the general duties expected of employees in the banking sector. These were answered by supervisors. Sample items include "employees demonstrate appropriate knowledge of banking practices and policies relevant to their positions" and "employees demonstrate appropriate interactions with the bank's customers".

\section{Evaluation of the measurement model}

The robustness of the measurement scales - abusive supervision, CWB, emotional dissonance, guilt-proneness and job performance - was tested using a two-step CFA. Robustness is determined in terms of scale reliability, convergent validity and discriminant validity of the scales. Scale reliability was tested using the Cronbach's alpha (CA), composite reliability (CR) and the average variance extracted (AVE). The standard requirement is that both the CA and CR values should exceed 0.7 while the AVE scores are required to be 0.5 or better. It is evident from the reports in Tables 1-5 that the scores for AVEs, CA coefficients and $\mathrm{CR}$ scores were all suitable and exceeded the threshold values of 0.5 and 0.7 , respectively. These values demonstrated that the scales were reliable and predicted the observed attributes with minimum errors.

Convergent validity, on the other hand, was evaluated using two criteria. Firstly, the loadings of the manifest indicators on their respective constructs were expected to exceed 
the value of 0.5 and significant at 0.01 (Oyewobi, Windapo \& Rotimi, 2016). Secondly, the model fit indices were expected to conform to the generally accepted standards. Model fit indices used for accessing convergent validity in this work included the Chi-square $(\chi 2)$, the normed Chi-square $(\chi 2 / \mathrm{df})$, comparative fit index (CFI), root mean square error of approximation (RMSEA) and the standardized root mean residual (SRMR). For the required standard for each model fit index, consult Hair, Sarstedt, Ringle and Mena (2012). The CFA result of the four-subscale abusive supervision construct demonstrated acceptable fit: $\chi 2(2)=0.029$; $p=0.986$; normed $\chi 2=0.015$; CFI $=1.00$; RMSEA $=0.000$; and SRMR $=0.002$. All factor loadings (ranging from 0.708 to 0.995 ) were significant; revealing convergent validity. The twosubscale employee performance construct also showed acceptable fit: $\chi 2(4)=4.536 ; p=0.338$; normed $\chi 2=1.134$; CFI $=0.99$; RMSEA $=0.025$; and SRMR $=0.021$. Factor loadings were also significant and ranged from 0.736 to 0.887 . Thus, convergent validity was achieved.

The results of the two-subscale CWB were also found to be robust: $\chi 2$ (4) $=4.307$; $p=0.366$; normed $\chi 2=1.077$; CFI $=0.99$; RMSEA $=0.019$; and SRMR $=0.02$. All factor loadings (ranging from 0.758 to 0.959 ) were significant; showing convergent validity. Meanwhile, CFA results, consistent with Cohen et al. (2011), found two subscales of guilt proneness: negative behaviour evaluation and repair action. The results were also found to be good; indicating acceptable fitness: $\chi 2(2)=4.694 ; p=0.096$; normed $\chi 2=2.347$; $\mathrm{CFI}=0.97$; RSEA $=0.079$; and SRMR $=0.036$. All factor loadings (ranging from 0.704 to 0.984) were significant; showing convergent validity. The CFA of the two-subdimensional emotional dissonance also demonstrated a perfect fit: $\chi 2(4)=7.294 ; p=0.114$; normed $\chi 2=1.834 ; \mathrm{CFI}=0.98 ; \mathrm{RMSEA}=0.03$; and $\mathrm{SRMR}=0.02$. All factor loadings (ranging from 0.721 to 0.889 ) were significant; showing convergent validity.

Discriminant validity, on the other hand, was evaluated using two procedures. Firstly, the factor loadings were significantly higher compared to the highest cross-loadings. Again, all the AVEs are significantly higher than the highest shared variance demonstrative of strong discriminant validity. The AVE values were also within the accepted standards. There were no statistically significant items cross-loadings (Dadzie et al., 2012). These results demonstrated adequate discriminant validity. Based on Tables $1-5$, the measurement model was considered satisfactory with the evidence of adequate reliability, convergent validity and discriminant validity. Thus, we proceeded to test our hypotheses based on the theoretical model in Figure 1.

\section{Common method bias}

Several steps were taken to reduce common method bias (CMB) in this work. Procedurally, during the data collection phase, we undertook two pilot tests. One focusing on human resource experts and the other sampling the responses of private sector managers and employees. The pilot study was done in separate periods; with the expert focused pre-test study conducted first to extract useful ideas and suggestions to contextualize the research instrument to the Ghanaian setting. The second pre-test study was then to identify difficulties and complications in the instrumentation. The structured questionnaire was finally administered across a sample of banking institutions; as this was the actual focus of the work. As already indicated, the final instrument was administered in two sessions. The first study obtained measures from employees who responded to questions on abusive supervision, guilt-proneness and emotional dissonance. The second study obtained measures from supervisors who responded to subordinates' CWB and job performance. These procedural steps were executed to reduce potential CMB. Despite the aforementioned procedures, $\mathrm{CMB}$ was also statistically assessed. An unmeasured latent variable was
Trickle-down model of abusive supervision 
OMJ

$18,3 / 4$

Table 2.

Correlation and descriptive statistics

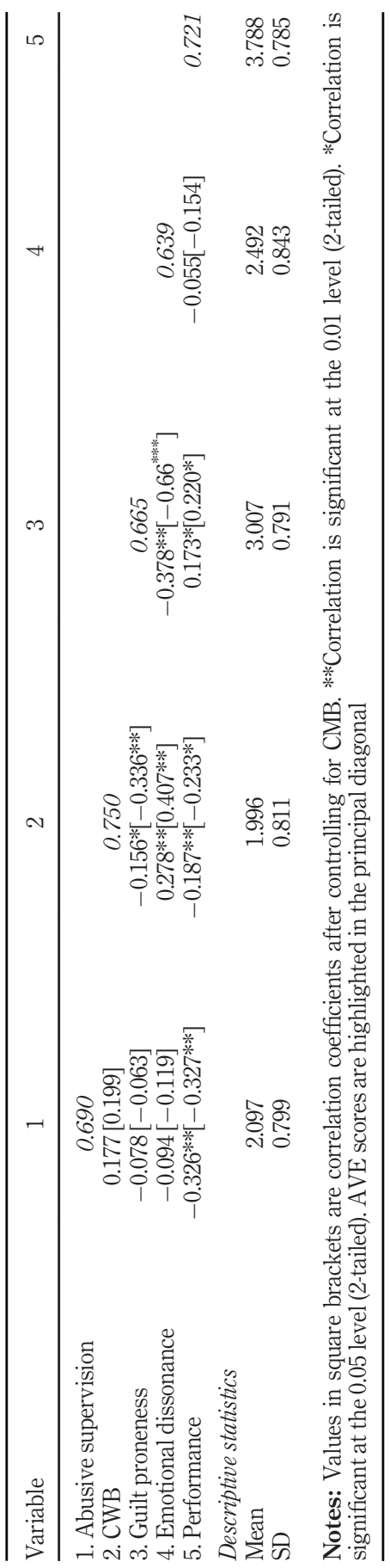


created and partialled out accordingly. The results provide evidence that $\mathrm{CMB}$ is not a problem in this work (Table 2).

\section{Results}

The theoretical framework as illustrated in Figure 1 is evaluated; with all the hypothesized relationships empirically tested using the structural equation modelling (SEM) technique. Literature indicates that SEM is a useful procedure when exploring mediating and moderating effects of observed variables while controlling for measurement errors. Two outcome variables were involved in the modelling (job performance and CWB). The SEM was estimated using the second-order constructs (Table 1 ).

Table 3 reports the results of the SEM which are then used to test the hypotheses developed. As reported, abusive supervision was found to have a significant negative relationship with job performance $(B=-0.288 ; p<0.01)$. This relationship gives strong support to $H 1$, which indicates that abusive supervision has a negative relationship with job performance. Meanwhile, $H 2 a$ proposes a positive relationship between abusive supervision and CWB. The SEM estimation reveals that abusive supervision has a strong positive influence on CWB $(B=0.227 ; p<0.01)$. Thus, $H 2 a$ was also supported. Concerning the relationship between $\mathrm{CWB}$ and job performance, it was purported by $H 2 b$ that $\mathrm{CWB}$ negatively influences job performance. This relationship was also supported by the SEM results $(B=-0.392 ; p<0.01)$. A test was likewise conducted on $H 3 a$ by analysing the effect of guilt-proneness on CWB. The standardized path coefficient confirmed that guiltproneness has a negative influence on $\operatorname{CWB}(B=-0.162 ; p<0.01)$.

We similarly found adequate empirical support for $H 3 c$, which asserted that guiltproneness positively influences job performance $(B=0.248$; $p<0.01)$. Equally, the study explored the effect of emotional dissonance on job performance as postulated by $H 4 a$. We found ample evidence to support the hypothesis that emotional dissonance negatively influences job performance $(B=-0.118 ; p<0.10)$. Testing the moderating effects of guiltproneness and emotional dissonance, Table 3 reports that the interaction of abusive supervision and guilt-proneness has a strong influence on CWB (abusive $\times$ guilt proneness:

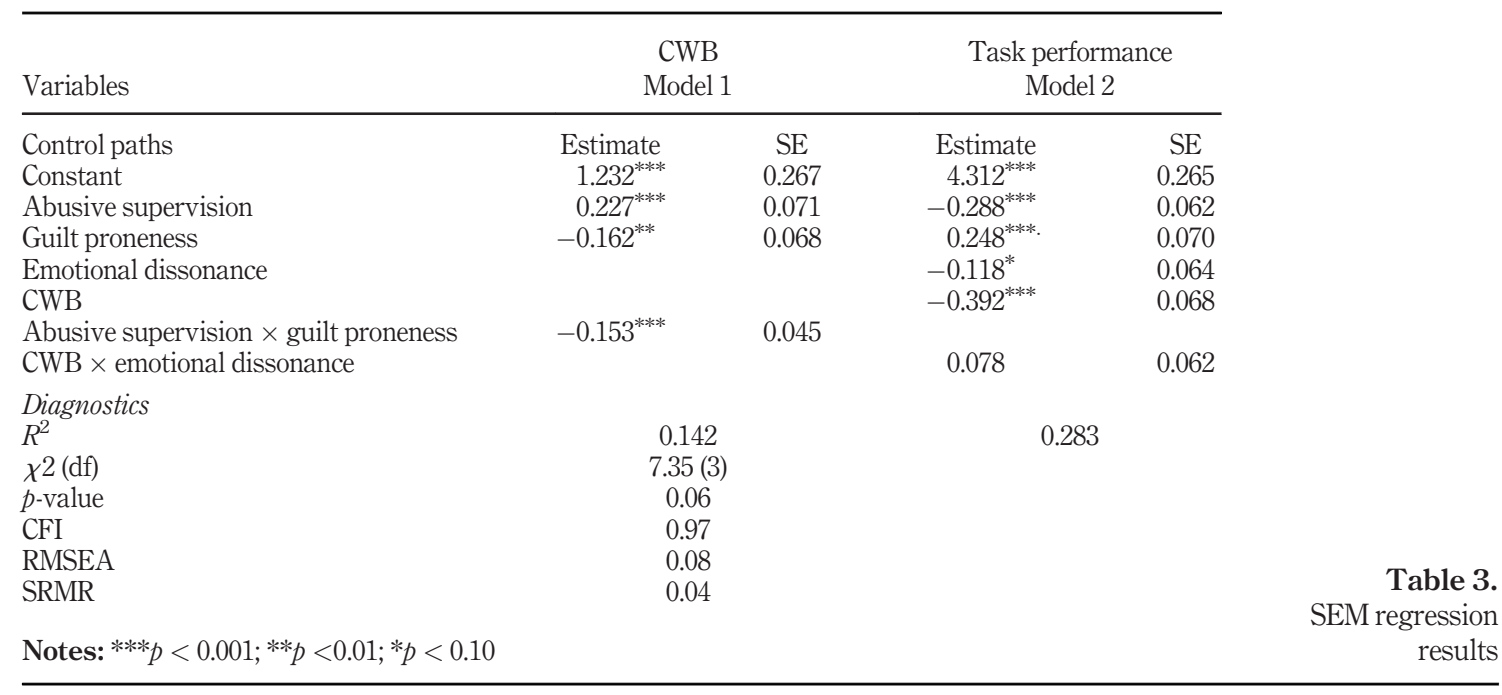

Trickle-down model of abusive supervision

133
(2) 
$\mathrm{OMJ}$

$18,3 / 4$

\section{4}

$B=-0.153 ; p<0.01)$. This finding gives strong support for $H 3 b$, which illustrates that guilt-proneness significantly moderates the relationship between abusive supervision and CWB. We extended the analysis further by testing for $H 4 b$, which asserted that emotional dissonance moderates the relationship between CWB and job performance. The standardized path coefficient showed that the negative effect of CWB on performance does not change significantly under different levels of emotional dissonance. Thus, emotional dissonance does not moderate the relationship between CWB and performance $(B=-0.078$; $p>0.10)$. Hence, $H 4 b$ was not supported.

To examine the mediating role of $\mathrm{CWB}$, our proposed model was compared to other variant models: no mediation model $[\Delta \chi 2(1)=48.35 ; p=0.00 ; \Delta \mathrm{CFI}=0.58 ; \Delta$ RMSEA $=-0.18$; $\Delta \mathrm{SRMR}=-0.06]$ and the full mediation model $[\Delta \chi 2(1)=68.65 ; p=0.00 ; \Delta \mathrm{CFI}=0.71$; $\Delta$ RMSEA $=-0.21 ; \Delta \mathrm{SRMR}=-0.06]$. The indices of the goodness of fit show that the proposed model (partial mediation model) performed better. Based on the partial mediation model, consequently, the indirect effect of abusive supervision through CWB was estimated. Results presented in Table 4 confirmed that abusive supervision has an indirect effect on performance through CWB $(B=-0.089 ; p<0.01)$. To calculate the size of the indirect effect, the variance accounted for (VAF) value, which is the ratio of indirect effect to the total effect, was measured. The VAF value indicates that $23.6 \%$ of the total effect of abusive supervision on job performance is explained by the indirect effect through CWB. Based on this finding, we conclude that CWB partially mediates the relationship between abusive supervision and job performance. Thus, $H 2 c$ received support. Furthermore, the indirect effect of the interaction of guilt-proneness and abusive supervision on performance through CWB was assessed. Results show that the moderating effect of guilt-proneness on the relationship between abusive supervision and performance is also mediated by CWB $(B=0.06 ; p<0.01)$. There was therefore adequate support for $H 3 d$. Meanwhile, the R-squared values (0.283 and 0.142$)$ were higher than the validated $10 \%$ as suggested in the literature.

Finally, to verify $H 4 c$ regarding the moderated mediation of CWB on job performance, a twogroup analysis was performed. We aimed to explore whether emotional dissonance moderates the mediated path from CWB to job performance. To achieve this, the data was split in terms of emotional dissonance as close to its median to constitute two sets of data (state 0 characterizing low levels of emotional dissonance with 116 sample size; and state 1 constituting high levels of emotional dissonance with 102 sample size). The results of the subgroup analysis were then compared to the Edwards and Lambert's (2007) procedure for testing moderated mediation. The results of the subgroup approach as demonstrated in Table 5 offered strong support for $\mathrm{H} 4 \mathrm{c}$. As shown, the mediation effect of CWB on the negative relationship between abusive supervision and job performance is enhanced in the state of low emotional dissonance $(B=-0.227 ; p<0.01)$ than in the state of high emotional dissonance $(B=-0.005 ; p>0.10)$.

The statistical test of difference shows a significant difference in the mediation effect of CWB among the two groups $(B=-0.222 ; p<0.01)$. The VAF is also shown to be higher $(32.1 \%)$ in the low emotional dissonance state than for the high emotional dissonance state $(1.9 \%)$. Moreover, the

Table 4.

Total and indirect effects

\begin{tabular}{lcrrr}
\hline & \multicolumn{2}{c}{ Total effect } & \multicolumn{2}{c}{ Indirect effect } \\
Variables & Estimate & SE & Estimate & SE \\
\hline Abusive supervision & $-0.377^{* * *}$ & 0.063 & $-0.089^{* * * *}$ & 0.016 \\
Guilt proneness & $0.312^{* * *}$ & 0.070 & $0.064^{* * *}$ & 0.017 \\
Abusive supervision $\times$ guilt proneness & $-0.153^{* * *}$ & 0.045 & $0.060^{* * *}$ & 0.021 \\
Note: $* * * *<0.001$ & & & & \\
\hline
\end{tabular}


explanatory power of the path model focusing on the moderating effect of high emotional dissonance is significantly lower $\left(R^{2}=0.195\right)$ than that of the path model concerning low emotional dissonance $\left(R^{2}=0.513\right)$. These observations are further confirmed by the Edwards and Lambert's (2007) procedure. As reported in Table 5 below, the indirect effect of abusive supervision through $\mathrm{CWB}$ is stronger among employees with low emotional dissonance $(B=$ $-0.049 ; p<0.1)$ relative to those with high emotional dissonance $(B=0.015 ; p>0.1)$. A comparison of these indirect effects shows a significant difference in the mediating role of $\mathrm{CWB}$ between low and high emotional dissonance $(\mathrm{B}=0.065 ; p<0.01)$.

Based on these findings, we can confidently conclude that the mediating effect of CWB in the abusive supervision-job performance relationship is moderated by emotional dissonance such that the impact of CWB on employees' performance is stronger when emotional dissonance levels are low rather than high. Moreover, further checks showed that the negative influence of CWB on job performance $(B=-0.630 ; p<0.01)$ is higher for low emotional dissonance cluster than in the case of high emotional dissonance $(B=-0.277$; $p<0.01)$. Thus, $H 4 c$ was supported.

The moderation plots are shown in Figures 2-4. Figure 2 demonstrates the interaction effect of abusive supervision and guilt-proneness on CWB. As indicated in Figure 2, under low levels of guilt-proneness, the impact of abusive supervision on performance is higher than at high levels of guilt-proneness. Figure 3 illustrates the interaction effect of CWB and emotional dissonance on performance. Figure 3 demonstrates that emotional dissonance has a measured influence on

\begin{tabular}{lcccrr}
\hline Outcome variable = Performance & First & Second & Direct effect & Indirect effect & Total effect \\
\hline Subgroup approach & & & & & \\
State 0 & - & - & $-0.483^{* * *}$ & $-0.227^{* * *}$ & $-0.710^{* * *}$ \\
State 1 & - & - & $-0.226^{* * *}$ & -0.005 & $-0.231^{* * *}$ \\
Difference & - & - & $0.257^{* * *}$ & $0.222^{* * *}$ & $0.479^{* * *}$ \\
Edwards and Lambert's (2007) approach & $0.126^{* *}$ & $-0.392^{* * *}$ & $-0.356^{* * *}$ & $-0.049^{*}$ & $-0.405^{* * *}$ \\
Low emotional dissonance & $-0.048^{* * *}$ & $-0.320^{* * *}$ & -0.078 & 0.015 & -0.063 \\
High emotional dissonance & $-0.174^{* *}$ & 0.072 & $0.278^{* * *}$ & $0.065^{* * *}$ & $0.343^{* * *}$ \\
Difference & & & &
\end{tabular}

Notes: $* * * p<0.001 ; * p<0.01$
Trickle-down model of abusive supervision 
$\mathrm{OMJ}$

$18,3 / 4$

136

Figure 3.

The moderating role of emotional dissonance

\section{Figure 4.}

Conditional mediated effect of emotional dissonance
CWB and job performance path relationship. Figure 4 shows the interactive effect of CWB and emotional dissonance on the relationship between abusive supervision and performance through CWB. As shown in Figure 4, the mediating effect of CWB is higher when emotional dissonance is lower than when emotional dissonance is higher.

\section{Discussion}

This study sought to extend the trickle-down model of abusive supervision by theoretically examining mediating and moderating dynamics of the abusive supervision-performance interface in a developing country. Grounded in the social exchange and norms of reciprocity, social learning and displaced aggression theories, we examined CWB as a pathway through which abusive supervision influences employees' performance. We further examined the interactions of guilt-proneness and emotional dissonance on the relationship. As predicted, our findings were largely consistent with the hypothesized model. Our study revealed that abusive supervision related positively to CWB corroborating with previous studies (An \& Wang, 2016; Eschleman et al., 2014; Ju et al., 2019), which in turn related negatively to employees' performance. Thus, the negative influence of perceived supervisor abuse on employee performance is instigated through CWB. This highlights the role that leaders play in initiating dysfunctional behaviours - the fish rots from the head down. There was also a negative relationship between abusive supervision and performance supporting other studies such as $\mathrm{Xu}$ et al. (2012) and Walter et al. (2015). The current study also examined guilt proneness as a
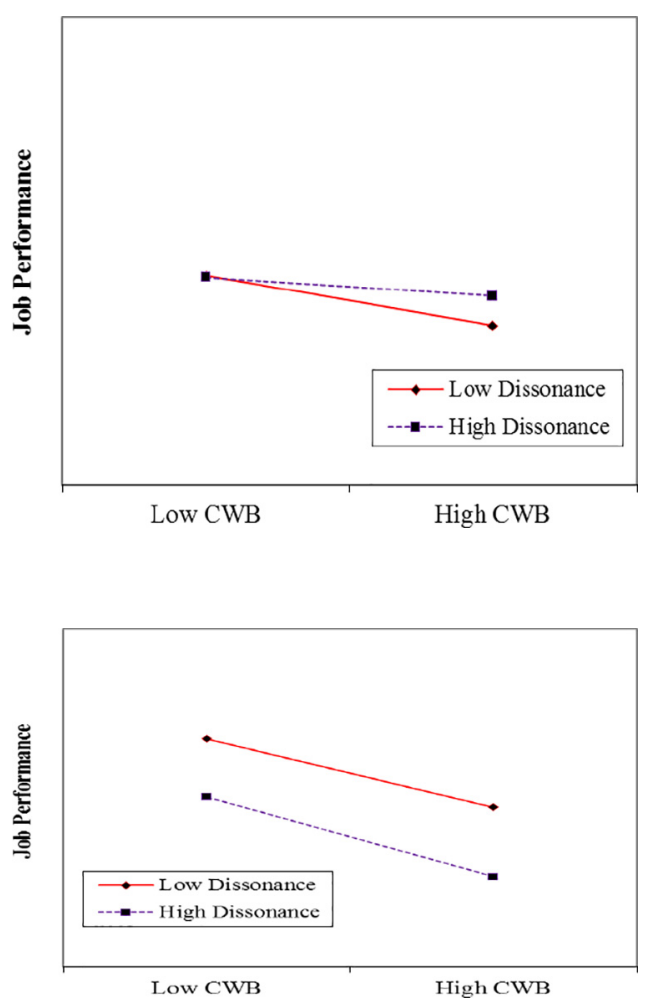
moderator in the path between abusive supervision and CWB. It was revealed that employees with high guilt-proneness engaged less in CWB and weakens the negative relationship between abusive supervision and CWB. Guilt proneness was also found to moderate the mediated effect of CWB in the abusive supervision-performance relationship. Our findings further revealed a negative relationship between emotional dissonance and employees' performance. Emotional dissonance was found to moderate the mediated effect of CWB in the abusive supervisionemployees' performance relationship such that the path relationship between CWB and employees' performance was stronger when emotional dissonance levels were low rather than high. The current study confirms that destructive behaviours trickle down from the leaders to subordinates in an exchange and reciprocal manner and that these exchanges are dependent on self-conscious and work-conscious emotions.

\section{Theoretical implications}

Theoretically, this study offers insight into the trickle-down effects of abusive supervision by testing a model that examines CWB as a mediator and two types of emotions as boundary conditions in retaliatory hostilities. Employees engage in social exchanges with their supervisors, but in doing so, they learn from the social environment what other supervisors and employees are exchanging. Extant literature largely supports that employees retaliate in response to abusive supervision. From the displaced aggression literature, individuals have a fundamental motivation to retaliate when experiencing mistreatment such as abusive supervision; however, it may be irrational given the possibility of aversive outcomes. In such instances where the employees cannot directly exchange negative behaviours, the employees displace their aggression on others including their organization. This retaliation against other targets other than the abusive supervisor restores a sense of justice. Based on this perspective, our study examined dysfunctional employees' behaviours as forms of displaced aggression in retaliation against abusive supervision. This study has confirmed that employees reciprocate with CWB and poor performance when abused by their leaders. Thus, the proliferation of dysfunctional behaviours is the results of abusive supervision. Our findings suggest that the pent-up resentments in employees, as a result of abusive supervision, are displaced by engaging in dysfunctional behaviours. This study contributes to the findings that behaviour trickle-down from leaders to subordinates.

Social relationships are heavily influenced by emotions and a full understanding of its role is needed to understand the leader-employee relationship and behaviours in the workplace. Our study adds to the current understanding of trickle-down of dysfunctional behaviours and suggests that employees may not always engage in CWB as a self-defeating response to abusive supervision (Tepper et al., 2015) because employees' guilt-proneness serves as a check on the retaliation process. Regardless of the nature of the social exchanges between leaders and subordinates, guilt-prone employees are motivated to make amends and work harder. Guilt is a positive emotional disposition that acts as a motivational force to promote increased performance and social harmony in organizations. The implication is that guilt-proneness, as a self-conscious emotion, restrains the engagement in deviance behaviours such as CWB.

In line with the belief that dysfunctional workplace behaviours should be understood in a context, our study accounts for the work context in determining the occurrence of dysfunctional organizational behaviours. In taking this approach, our study suggests that the extent of supervisors' dysfunctional behaviours influencing subordinates' dysfunctional behaviours is dependent on the work context. Our study has determined that the cascading effect of abusive supervision on CWB, which translates into poor performance, is reduced in a high emotional dissonance work environment. The implication is that the likelihood of employees engaging in dysfunctional behaviours in a high emotional dissonance work environment in response to
Trickle-down model of abusive supervision 
$\mathrm{OMJ}$ $18,3 / 4$

abusive supervision is low. Thus, the emotional demands of service-oriented work environment can mitigate against employees' engagement in dysfunctional behaviours. Additionally, support for the interactive perspectives suggests the need to adopt the condition bound perspective in social exchange and norms of reciprocity theories.

\section{Practical implications}

This study enhances understanding of how the social context of work discourages employees from exhibiting negative behaviours. The study is particularly useful to management because it explains the causes of these negative organizational behaviours. This study reveals that the negative actions of leaders beget negative reactions from employees. Employees engage in negative organizational behaviours in response to abusive supervision from their leaders. For employees to exhibit the desired organizational behaviours, leaders in their supervisory roles need to act as role models. A key aspect of leadership is the ability to influence. From this study, leaders can negatively influence their subordinates. This influence suggests the need for awareness training for leaders on the negative impact of abusing their supervisory roles. This awareness can be supported by an assessment by employees on their leaders' supervisory roles as part of performance measures. Secondly, organizations need to be more proactive in providing specific anonymous channels for reporting abusive supervisors and employees CWBs. These channels will promote a good working environment and improve performance.

Thirdly, this study suggests that employees high on guilt-proneness are assets to organizations. They self-examine and self-regulate their behaviour, exert greater effort at work, encourage positive energies and engage less in deviant behaviours. As part of the hiring criteria, employers should assess the guilt-proneness of applicants. Notwithstanding, such employees, when abused, are likely to voice out "with their feet" (quit) rather than engage in dysfunctional behaviours.

Given the nature of work in the service sector, it is unrealistic to eliminate the emotionally demanding aspect of the work. Organizations should rather come up with solutions on how to manage emotions well at work and also to provide avenues, such as psychological counselling, for the employees to vent their frustrations. Such management of emotions is important because emotional dissonance leads to poor performance. In championing the customer as the king, organizations are feeling the brunt of the "employee is always wrong". However, this study has also established that work characteristics of service organizations that demand that employees manage their feelings and expressions as part of the emotional requirement of the job have positive consequences. The management of emotions at work is important in curbing dysfunctional behaviours. Internal organizational support, such as wellness programs, should be provided for employees to vent.

\section{Limitations and directions for future research}

The limitations of this study should be noted for further studies. Firstly, abusive supervision was measured from the employees' perception of supervisors' abuse rather than objective abusive supervisor behaviours. This subjective assessment has been done in other research works (Lian et al., 2014a, 2014b), and Chan (2009) argues that self-reported data is the most valid approach for assessing perceptual construct. However, a more objective measure prevents perceptual bias as it has been found that subordinates' personalities affect their perception of abusive supervision (Henle \& Gross, 2014; Nandkeolyar et al., 2014; Wang, Harms \& Mackey, 2015). Secondly, the study used cross-sectional surveys and thus limits the inference of causality. Though the study obtained performance and CWB measures from supervisors in the second study, the use of alternative research designs will provide more credence to the causalities. Thirdly, data was obtained from the branches of one bank in an emerging economy, thus limiting the generalizability 
of the findings. Future research may replicate this study in multiple organizations across different sectors. Fourthly, though the study used a multi-sourcing of data, four of the measures were from a single source. There could be the potential of CMB. However, the reported CMB analysis (Table 2) revealed no such problem. Moreover, two significant interaction effects were revealed in this study and according to Siemsen, Roth and Oliveira (2010), interaction effects are difficult to detect when $\mathrm{CMB}$ is present. Lastly, from the social exchange theory, an initiating action (e.g. abusive supervision) results in two subtypes of reciprocating responses - relational and behavioural responses (Cropanzano et al., 2017). This study focused on behavioural responses (CWB and performance). Further studies are needed to assess both behavioural responses and relational responses, such as commitment and trust, in a single study to comprehensively understand the exchanges in organizations.

\section{Conclusion}

This study provides useful explanations of the trickle-down effects of abusive supervision on workplace behaviour. Using multiple theories, this study has established that workers reciprocate the abusive behaviours of supervisors by displacing their anger on organizations. The tone of behaviours in organizations is set by leaders and modelled by employees. Employees' behaviours are, thus, reflections of leadership behaviours. Undoubtedly, these findings are important in shaping the understanding of the role played by supervisors, either consciously or unconsciously, in shaping organizational climates and employees' behaviour. However, employees' emotional traits and the emotional demands of their work determine the extent of their responsiveness to abusive supervision and negative organizational behaviours.

\section{References}

Abas, N. A. H. B. \& Otto, K. (2016). Interpersonal mistreatment, organizational attitudes and well-being: the impact of instigator's hierarchical position and demographic characteristics. Organization Management Journal, 13(1), 5-20. doi: 10.1080/15416518.2015.1129307.

Ambrose, M. L., Schminke, M., \& Mayer, D. M. (2013). Trickle-down effects of supervisor perceptions of interactional justice: a moderated mediation approach. Journal of Applied Psychology, 98(4), 678 doi: $10.1037 / a 0032080$.

An, F. \& Wang, B. (2016). Abusive supervision and counterproductive work behavior: Moderating effect of negative affectivity. Journal of Service Science and Management, 09(1), 66-73. doi: 10.4236/jssm.2016.91009.

Andersson, L. M. \& Pearson, C. M. (1999). Tit for tat? The spiralling effect of incivility in the workplace. Academy of Management Review, 24(3), 452-471. doi: 10.5465/amr.1999.2202131.

Anjum, M. A. \& Parvez, A. (2013). Counterproductive behavior at work: a comparison of blue-collar and white-collar workers. Pakistan Journal of Commerce and Social Sciences, 7(3), 417-434.

Aronson, E. (2001). Integrating leadership styles and ethical perspectives. Canadian Journal of Administrative Sciences/Revue Canadienne Des Sciences de L'administration, 18(4), 244-256. doi: 10.1111/j.1936-4490.2001.tb00260.x.

Aryee, S., Sun, L., Chen, Z. X., \& Debrah, Y. A. (2008). Abusive supervision and contextual performance: the mediating role of emotional exhaustion and the moderating role of work unit structure. Management and Organization Review, 4(3), 393-411. doi: 10.1111/j.1740-8784.2008.00118.x.

Ashforth, B. (1994). Petty tyranny in organizations. Human Relations, 47(7), 755-778. doi: 10.1177/ 001872679404700701.

Bailey, J. J. \& McCollough, M. (2000). Emotional labor and the difficult customer: coping strategies of service agents and organisational consequences. Journal of Professional Services Marketing, 20(2), 51-72. doi: 10.1300/J090v20n02_05.

\section{Trickle-down model of abusive supervision}

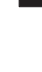


$\mathrm{OMJ}$ $18,3 / 4$

Bakker, A. B. \& Heuven, E. (2006). Emotional dissonance, burnout, and in-role performance among nurses and police officers. International Journal of Stress Management, 13(4), 423 doi: 10.1037/ 1072-5245.13.4.423.

Bandura, A. (1977). Social Learning Theory, Englewood Cliffs, NJ: Prentice-Hall.

Blau, P. M. (1964). Exchange and power in social life Piscataway, Piscataway: Transaction Publishers.

Bordia, P., Restubog, S. L. D., Bordia, S., \& Tang, R. L. (2010). Breach begets breach: Trickle-down effects of psychological contract breach on customer service. Journal of Management, 36(6), 1578-1607. doi: 10.1177/0149206310378366.

Burton, J. P. \& Hoobler, J. M. (2011). Aggressive reactions to abusive supervision: the role of interactional justice and narcissism. Scandinavian Journal of Psychology, 52(4), 389-398. doi: 10.1111/j.1467-9450.2011.00886.x.

Chan, D. (2009). So why ask me? Are self-report data really that bad. Statistical and Methodological Myths and Urban Legends: Doctrine, Verity and Fable in the Organizational and Social Sciences, 309-336.

Cohen, T. R., Kim, Y., \& Panter, A. T. (2014). The five-item guilt proneness scale (GP-5). Differences, 92, 109-112.

Cohen, T. R., Panter, A. T., \& Turan, N. (2013). Predicting counterproductive work behaviour from guilt proneness. Journal of Business Ethics, 114(1), 45-53. doi: 10.1007/s10551-012-1326-2.

Cohen, T. R., Wolf, S. T., Panter, A. T., \& Insko, C. A. (2011). Introducing the GASP scale: a new measure of guilt and shame proneness. Journal of Personality and Social Psychology, 100(5), 947-966. doi: 10.1037/a0022641.

Crego, A., Martinez-Inigo, D., \& Tschan, F. (2013). Moderating effects of attributions on the relationship between emotional dissonance and surface acting: a transactional approach to health care professionals' emotion work. Journal of Applied Social Psychology, 43(3), 570-581. doi: 10.1111/ j.1559-1816.2013.01037.x.

Cropanzano, R., Anthony, E. L., Daniels, S. R., \& Hall, A. V. (2017). Social exchange theory: a critical review with theoretical remedies. Academy of Management Annals, 11(1), 479-516. doi: 10.5465/ annals.2015.0099.

Dadzie, C. A., Winston, E. M., \& Dadzie, K. Q. (2012). Organizational culture, competitive strategy, and performance in Ghana. Journal of African Business, 13(3), 172-182.

Dartey-Baah, K. \& Ampofo, E. Y. (2015). Examining the influence of transformational and transactional leadership styles on perceived job stress among Ghanaian banking employees. International Journal of Business and Management, 10(8), 161 doi: 10.5539/ijbm.v10n8p161.

Diefendorff, J. M., Richard, E. M., \& Croyle, M. H. (2006). Are emotional display rules formal job requirements? Examination of employee and supervisor perceptions. Journal of Occupational and Organizational Psychology, 79(2), 273-298. doi: 10.1348/096317905X68484.

Dollard, J., Miller, N. E., Doob, L. W., Mowrer, O. H., \& Sears, R. R. (1939). Frustration and Aggression, New Haven, CT: Yale University Press.

Duffy, M. K., Ganster, D. C., \& Pagon, M. (2002). Social undermining in the workplace. Academy of Management Journal, 45(2), 331-351.

Edwards, J. R. \& Lambert, L. S. (2007). Methods for integrating moderation and mediation: a general analytical framework using moderated path analysis. Psychological Methods, 12(1), 1 doi: 10.1037/1082-989X.12.1.1.

Eisenberger, R., Lynch, P., Aselage, J., \& Rohdieck, S. (2004). Who takes the most revenge? Individual differences in negative reciprocity norm endorsement. Personality and Social Psychology Bulletin, 30(6), 787-799. doi: 10.1177/0146167204264047.

Eschleman, K. J., Bowling, N. A., Michel, J. S., \& Burns, G. N. (2014). Perceived intent of supervisor as a moderator of the relationships between abusive supervision and counterproductive work behaviours. Work \& Stress, 28(4), 362-375. 
Flynn, F. J. \& Schaumberg, R. L. (2012). When feeling bad leads to feeling good: Guilt-proneness and affective organizational commitment. Journal of Applied Psychology, 97(1), 124 doi: 10.1037/a0024166.

Gouldner, A. W. (1960). The norm of reciprocity: a preliminary statement. American Sociological Review, 1, 161-178.

Grandey, A. A., Kern, J. H., \& Frone, M. R. (2007). Verbal abuse from outsiders versus insiders: Comparing frequency, impact on emotional exhaustion, and the role of emotional labor. Journal of Occupational Health Psychology, 12(1), 63 doi: 10.1037/1076-8998.12.1.63.

Hair, J. F., Sarstedt, M., Ringle, C. M., \& Mena, J. A. (2012). An assessment of the use of partial least squares structural equation modeling in marketing research. Journal of the Academy of Marketing Science, 40(3), 414-433. doi: 10.1007/s11747-011-0261-6.

Henle, C. A. \& Gross, M. A. (2014). What have I done to deserve this? Effects of employee personality and emotion on abusive supervision. Journal of Business Ethics, 122(3), 461-474. doi: 10.1007/ s10551-013-1771-6.

Hershcovis, M. S. (2011). "Incivility, social undermining, bullying ... oh my!": A call to reconcile constructs within workplace aggression research. Journal of Organizational Behavior, 32(3), 499-519.

Hershcovis, M. S., Turner, N., Barling, J., Arnold, K. A., Dupré, K. E., Inness, M., \& Sivanathan, N. (2007). Predicting workplace aggression: a meta-analysis. Journal of Applied Psychology, 92(1), 228.

Hochschild, A. (1983). The Managed Heart, Berkeley: University of CA Press.

Hoobler, J. M. \& Hu, J. (2013). A model of injustice, abusive supervision, and negative affect. The Leadership Quarterly, 24(1), 256-269. doi: 10.1016/j.leaqua.2012.11.005.

Jordan, J., Flynn, F. J., \& Cohen, T. R. (2015). Forgive them for I have sinned: the relationship between guilt and forgiveness of others' transgressions. European Journal of Social Psychology, 45(4), 441-459. doi: 10.1002/ejsp.2101.

Ju, D., Xu, M., Qin, X., \& Spector, P. (2019). A multilevel study of abusive supervision, norms, and personal control on counterproductive work behavior: a theory of planned behavior approach. Journal of Leadership \& Organizational Studies, 26(2), 163-178.

Karakitapoğlu-Aygün, Z. \& Gumusluoglu, L. (2013). The bright and dark sides of leadership: Transformational vs. non-transformational leadership in a non-Western context. Leadership, 9(1), 107-133. doi: 10.1177/1742715012455131.

Kim, Y. \& Cohen, T. R. (2015). Moral character and workplace deviance: Recent research and current trends. Current Opinion in Psychology, 6, 134-138. doi: 10.1016/j.copsyc.2015.08.002.

Klotz, A. C. \& Buckley, M. R. (2013). A historical perspective of counterproductive work behaviour targeting the organisation. Journal of Management History, 19(1), 114-132. doi: 10.1108/ 17511341311286222.

Lian, H., Ferris, D. L., Morrison, R., \& Brown, D. J. (2014a). Blame it on the supervisor or the subordinate? Reciprocal relations between abusive supervision and organisational deviance. Journal of Applied Psychology, 99(4), 651 doi: 10.1037/a0035498.

Lian, H., Brown, D. J., Ferris, D. L., Liang, L. H., Keeping, L. M., \& Morrison, R. (2014b). Abusive supervision and retaliation: a self-control framework. Academy of Management Journal, 57(1), 116-139. doi: 10.5465/amj.2011.0977.

Liang, L. H., Brown, D. J., Lian, H., Hanig, S., Ferris, D. L., \& Keeping, L. M. (2018). Righting a wrong: Retaliation on a voodoo doll symbolizing an abusive supervisor restores justice. The Leadership Quarterly, 29(4), 443-456. doi: 10.1016/j.leaqua.2018.01.004.

Liu, D., Liao, H., \& Loi, R. (2012). The dark side of leadership: a three-level investigation of the cascading effect of abusive supervision on employee creativity. Academy of Management Journal, 55(5), 1187-1212. doi: 10.5465/amj.2010.0400.

Lyons, B. J. \& Scott, B. A. (2012). Integrating social exchange and affective explanations for the receipt of help and harm: a social network approach. Organizational Behavior and Human Decision Processes, 117(1), 66-79. doi: 10.1016/j.obhdp.2011.10.002.
Trickle-down model of abusive supervision 
$\mathrm{OMJ}$ $18,3 / 4$

Mackey, J., Kane, R., Perrewe, P., \& Gallagher, V. C. (2013). Abusive supervision and the high impact employee: Hurting our most valuable resource: received wisdom, kernels of truth, and boundary conditions in organizational studies. Research in Organizational Sciences, 1, 105-119.

Macovei, C. M. (2016). Counterproductive behaviors and work performance in military organization. International Conference Knowledge-Based Organization, 22(2), 444-450. doi: 10.1515/kbo-2016-0076.

Martinko, M. J., Harvey, P., Brees, J. R., \& Mackey, J. (2013). A review of abusive supervision research. Journal of Organizational Behavior, 34(S1), S120-S137. doi: 10.1002/job.1888.

Masterson, S. S. (2001). A trickle-down model of organizational justice: relating employees' and customers' perceptions of and reactions to fairness. Journal of Applied Psychology, 86(4), 594 doi: 10.1037/0021-9010.86.4.594.

Mawritz, M. B., Mayer, D. M., Hoobler, J. M., Wayne, S. J., \& Marinova, S. V. (2012). A trickle-down model of abusive supervision. Personnel Psychology, 65(2), 325-357. doi: 10.1111/j.17446570.2012.01246.x.

Mayer, D. M., Kuenzi, M., Greenbaum, R., Bardes, M., \& Salvador, R. B. (2009). How low does ethical leadership flow? Test of a trickle-down model. Organizational Behavior and Human Decision Processes, 108(1), 1-13. doi: 10.1016/j.obhdp.2008.04.002.

Molino, M., Emanuel, F., Zito, M., Ghislieri, C., Colombo, L., \& Cortese, C. G. (2016). Inbound call centers and emotional dissonance in the job demands-resources model. Frontiers in Psychology, 07 doi: 10.3389/fpsyg.2016.01133.

Morris, J. A. \& Feldman, D. C. (1996). The dimensions, antecedents, and consequences of emotional labor. Academy of Management Review, 21(4), 986-1010. doi: 10.5465/amr.1996.9704071861.

Morrison, T. \& Wonnacott, J. (2010). Supervision: Now or Never Reclaiming Reflective Supervision in Social Work. London: Social Work Reform Board, Retrieved from www.education.gov.uk/swrb/ employers/a0074263/standardsfor-employers-and-supervision-framework (accessed 13 March).

Nandkeolyar, A. K., Shaffer, J. A., Li, A., Ekkirala, S., \& Bagger, J. (2014). Surviving an abusive supervisor: the joint roles of conscientiousness and coping strategies. Journal of Applied Psychology, 99(1), 138 doi: 10.1037/a0034262.

Osei, H. V., Osei-Kwame, D., \& Osei Amaniampong, L. (2017). The effects of individual mechanisms on work self-efficacy of nurses: the mediating role of organisational commitment. International Journal of Healthcare Management, 10(4), 219-237. doi: 10.1080/20479700.2016.1268798.

Oxford Business Group. (2016). The report: Ghana 2016. Retrieved from www.oxfordbusinessgroup. com/ghana-2016/banking (accessed 6 February 2017).

Oyewobi, L. O., Windapo, A. O., \& Rotimi, J. O. (2016). Environment, competitive strategy, and organisational characteristics: a path analytic model of construction organisations' performance in South Africa. Canadian Journal of Administrative Sciences/Revue Canadienne Des Sciences de L'administration, 33(3), 213-226. doi: 10.1002/cjas.1384.

Paunov, M. (2010). Organizational consequences and individual antecedents of emotional dissonance and emotional labor. Economic Alternatives, 4(2), 23-39.

Penney, L. M. \& Spector, P. E. (2005). Job stress, incivility, and counterproductive work behavior (CWB): the moderating role of negative affectivity. Journal of Organizational Behavior, 26(7), 777-796. doi: 10.1002/job.336.

Restubog, S. L. D., Scott, K. L., \& Zagenczyk, T. J. (2011). When distress hits home: the role of contextual factors and psychological distress in predicting employees' responses to abusive supervision. Journal of Applied Psychology, 96(4), 713 doi: 10.1037/a0021593.

Robinson, S. L. \& Bennett, R. J. (1995). A typology of deviant workplace behaviors: a multidimensional scaling study. Academy of Management Journal, 38(2), 555-572.

Shoss, M. K., Eisenberger, R., Restubog, S. L. D., \& Zagenczyk, T. J. (2013). Blaming the organisation for abusive supervision: the roles of perceived organisational support and supervisor's organisational embodiment. Journal of Applied Psychology, 98(1), 158 doi: 10.1037/a0030687. 
Shoss, M. K., Jundt, D. K., Kobler, A., \& Reynolds, C. (2016). Doing bad to feel better? An investigation of within-and between-person perceptions of counterproductive work behavior as a coping tactic. Journal of Business Ethics, 137(3), 571-587. doi: 10.1007/s10551-015-2573-9.

Siemsen, E., Roth, A., \& Oliveira, P. (2010). Common method bias in regression models with linear, quadratic, and interaction effects. Organizational Research Methods, 13(3), 456-476. doi: $10.1177 / 1094428109351241$.

Spector, P. E. \& Fox, S. (2005). The stressor-emotion model of counterproductive work behaviour. In P. E. Spector \& S. Fox, (Eds.), Counterproductive Work Behaviour: Investigation of Actors and Targets. Washington, DC: APA Books. 151-174

Spector, P. E. \& Fox, S. (2010). Theorizing about the deviant citizen: an attributional explanation of the interplay of organizational citizenship and counterproductive work behavior. Human Resource Management Review, 20(2), 132-143. doi: 10.1016/j.hrmr.2009.06.002.

Spector, P. E., Fox, S., Penney, L. M., Bruursema, K., Goh, A., \& Kessler, S. (2006). The dimensionality of counterproductivity: Are all counterproductive behaviors created equal? Journal of Vocational Behavior, 68(3), 446-460. doi: 10.1016/j.jvb.2005.10.005.

Sulea, C., Fine, S., Fischmann, G., Sava, F. A., \& Dumitru, C. (2013). Abusive supervision and counterproductive work behaviours: the moderating effects of personality. Journal of Personnel Psychology, 12(4), 196-200. doi: 10.1027/1866-5888/a000097.

Tepper, B. J. (2000). Consequences of abusive supervision. Academy of Management Journal, 43(2), 178-190.

Tepper, B. J. (2007). Abusive supervision in work organizations: Review, synthesis, and research agenda. Journal of Management, 33(3), 261-289. doi: 10.1177/0149206307300812.

Tepper, B. J., Moss, S. E., \& Duffy, M. K. (2011). Predictors of abusive supervision: Supervisor perceptions of deep-level dissimilarity, relationship conflict, and subordinate performance. Academy of Management Journal, 54(2), 279-294. doi: 10.5465/amj.2011.60263085.

Tepper, B. J., Mitchell, M. S., Haggard, D. L., Kwan, H. K., \& Park, H. M. (2015). On the exchange of hostility with supervisors: an examination of self-enhancing and self-defeating perspectives. Personnel Psychology, 68(4), 723-758. doi: 10.1111/peps.12094.

Tepper, B. J., Carr, J. C., Breaux, D. M., Geider, S., Hu, C., \& Hua, W. (2009). Abusive supervision, intentions to quit, and employees' workplace deviance: a power/dependence analysis. Organizational Behavior and Human Decision Processes, 109(2), 156-167. doi: 10.1016/j.obhdp.2009.03.004.

Thau, S., Bennett, R. J., Mitchell, M. S., \& Marrs, M. B. (2009). How management style moderates the relationship between abusive supervision and workplace deviance: an uncertainty management theory perspective. Organizational Behavior and Human Decision Processes, 108(1), 79-92. doi: 10.1016/j.obhdp.2008.06.003.

Valle, M., Kacmar, K. M., Zivnuska, S., \& Harting, T. (2019). Abusive supervision, leader-member exchange, and moral disengagement: a moderated-mediation model of organizational deviance. The Journal of Social Psychology, 159(3), 299-312. doi: 10.1080/00224545.2018.1466776.

van Gelderen, B. R., Konijn, E. A., \& Bakker, A. B. (2017). Emotional labor among police officers: a diary study relating strain, emotional labor, and service performance. The International Journal of Human Resource Management, 28(6), 852-879. doi: 10.1080/09585192.2016.1138500.

Walter, F., Lam, C. K., Van der Vegt, G. S., Huang, X., \& Miao, Q. (2015). Abusive supervision and subordinate performance: Instrumentality considerations in the emergence and consequences of abusive supervision. Journal of Applied Psychology, 100(4), 1056 doi: 10.1037/a0038513.

Wang, G., Harms, P. D., \& Mackey, J. D. (2015). Does it take two to tangle? Subordinates' perceptions of and reactions to abusive supervision. Journal of Business Ethics, 131(2), 487-503. doi: 10.1007/s10551-014$2292-7$.

Warburton, W. A. \& Anderson, C. A. (2015). Aggression, social psychology of. International Encyclopedia of the Social \& Behavioral Sciences, 1, 373-380.

Wei, F. \& Si, S. (2013). Tit for tat? Abusive supervision and counterproductive work behaviors: the moderating effects of locus of control and perceived mobility. Asia Pacific Journal of Management, 30(1), 281-296. doi: 10.1007/s10490-011-9251-y. 
$\mathrm{OMJ}$

$18,3 / 4$

Wo, D. X., Ambrose, M. L., \& Schminke, M. (2015). What drives trickle-down effects? A test of multiple mediation processes. Academy of Management Journal, 58(6), 1848-1868. doi: 10.5465/ amj.2013.0670.

Xu, E., Huang, X., Lam, C. K., \& Miao, Q. (2012). Abusive supervision and work behaviors: the mediating role of LMX. Journal of Organizational Behavior, 33(4), 531-543. doi: 10.1002/job.768.

Yagil, D. (2012). The mediating role of engagement and burnout in the relationship between employees' emotion regulation strategies and customer outcomes. European Journal of Work and Organizational Psychology, 21(1), 150-168. doi: 10.1080/1359432X.2011.557549.

Yam, K. C., Fehr, R., Keng-Highberger, F. T., Klotz, A. C., \& Reynolds, S. J. (2016). Out of control: a selfcontrol perspective on the link between surface acting and abusive supervision. Journal of Applied Psychology, 101(2), 292 doi: 10.1037/ap10000043.

Zapf, D. (2002). Emotion work and psychological well-being: a review of the literature and some conceptual considerations. Human Resource Management Review, 12(2), 237-268. doi: 10.1016/ S1053-4822(02)00048-7.

Zapf, D. \& Holz, M. (2006). On the positive and negative effects of emotion work in organizations. European Journal of Work and Organizational Psychology, 15(1), 1-28. doi: 10.1080/13594320500412199.

Zellars, K. L., Tepper, B. J., \& Duffy, M. K. (2002). Abusive supervision and subordinates' organizational citizenship behavior. Journal of Applied Psychology, 87(6), 1068 doi: 10.1037/00219010.87.6.1068.

Zhu, X. M., Lian, X., Hao, L. F., \& Ding, T. D. (2015). The impact of abusive supervision on employees' counterproductive work behavior: the mediating role of emotional exhaustion. Journal of East China Economic Management, 29, 128-133.

\section{Further reading}

Fornell, C. \& Larcker, D. F. (1981). Evaluating structural equation models with unobservable variables and measurement error. Journal of Marketing Research, 18(1), 39-50. doi: 10.1177/002224378101800104.

Inness, M., Barling, J., \& Turner, N. (2005). Understanding supervisor-targeted aggression: a withinperson, between-jobs design. Journal of Applied Psychology, 90(4), 731 doi: 10.1037/00219010.90.4.731.

Kermond, C. M. Y. (2014). Abusive subordination: a multilevel model of abusive subordination. Academy of Management Proceedings, 2014(1), 13107 doi: 10.5465/ambpp.2014.13107abstract.

Lewig, K. A. \& Dollard, M. F. (2003). Emotional dissonance, emotional exhaustion and job satisfaction in call Centre workers. European Journal of Work and Organizational Psychology, 12(4), 366-392. doi: 10.1080/13594320344000200.

Liu, J., Kwong Kwan, H., Wu, L. Z., \& Wu, W. (2010). Abusive supervision and subordinate supervisordirected deviance: the moderating role of traditional values and the mediating role of revenge cognitions. Journal of Occupational and Organizational Psychology, 83(4), 835-856. doi: 10.1348/ $096317909 X 485216$.

Corresponding author

Hannah Vivian Osei can be contacted at: haviv7@yahoo.com

For instructions on how to order reprints of this article, please visit our website:

www.emeraldgrouppublishing.com/licensing/reprints.htm

Or contact us for further details: permissions@emeraldinsight.com 